\title{
Inhaled ambient-level traffic-derived particulates decrease cardiac vagal influence and baroreflexes and increase arrhythmia in a rat model of metabolic syndrome
}

Alex P. Carll ${ }^{1,2^{*}}$, Samir M. Crespo ${ }^{1,3}$, Mauricio S. Filho ${ }^{1,3}$, Douglas H. Zati1,3, Brent A. Coull', Edgar A. Diaz', Rodrigo D. Raimundo ${ }^{1,4}$, Thomas N. G. Jaeger ${ }^{1,3}$, Ana Laura Ricci-Vitor ${ }^{1,5}$, Vasileios Papapostolou', Joy E. Lawrence ${ }^{1}$, David M. Garner ${ }^{6}$, Brigham S. Perry ${ }^{1}$, Jack R. Harkema ${ }^{7}$ and John J. Godleski ${ }^{1}$

\begin{abstract}
Background: Epidemiological studies have linked exposures to ambient fine particulate matter $\left(\mathrm{PM}_{2.5}\right)$ and traffic with autonomic nervous system imbalance (ANS) and cardiac pathophysiology, especially in individuals with preexisting disease. It is unclear whether metabolic syndrome (MetS) increases susceptibility to the effects of $\mathrm{PM}_{2.5}$. We hypothesized that exposure to traffic-derived primary and secondary organic aerosols $(P+S O A)$ at ambient levels would cause autonomic and cardiovascular dysfunction in rats exhibiting features of MetS. Male Sprague Dawley (SD) rats were fed a high-fructose diet (HFrD) to induce MetS, and exposed to P + SOA $\left(20.4 \pm 0.9 \mu \mathrm{g} / \mathrm{m}^{3}\right)$ for 12 days with time-matched comparison to filtered-air (FA) exposed MetS rats; normal diet (ND) SD rats were separately exposed to FA or P + SOA $\left(56.3 \pm 1.2 \mu \mathrm{g} / \mathrm{m}^{3}\right)$.

Results: In MetS rats, P + SOA exposure decreased HRV, QTc, PR, and expiratory time overall (mean effect across the entirety of exposure), increased breathing rate overall, decreased baroreflex sensitivity (BRS) on three exposure days, and increased spontaneous atrioventricular (AV) block Mobitz Type II arrhythmia on exposure day 4 relative to FA-exposed animals receiving the same diet. Among ND rats, P + SOA decreased HRV only on day 1 and did not significantly alter BRS despite overall hypertensive responses relative to FA. Correlations between HRV, ECG, BRS, and breathing parameters suggested a role for autonomic imbalance in the pathophysiologic effects of P + SOA among MetS rats. Autonomic cardiovascular responses to $\mathrm{P}+\mathrm{SOA}$ at ambient $\mathrm{PM}_{2.5}$ levels were pronounced among MetS rats and indicated blunted vagal influence over cardiovascular physiology.
\end{abstract}

Conclusions: Results support epidemiologic findings that MetS increases susceptibility to the adverse cardiac effects of ambient-level $\mathrm{PM}_{2.5}$, potentially through ANS imbalance.

Keywords: Particulate matter, Secondary organic aerosol, Baroreflex, Heart rate variability, Autonomic, Arrhythmia, Traffic, Respiratory, Cardiopulmonary

\footnotetext{
* Correspondence: alex.carll@louisville.edu

'Department of Environmental Health, Harvard T.H. Chan School of Public Health, Boston, MA, USA

${ }^{2}$ Department of Physiology, Diabetes and Obesity Center, School of

Medicine, University of Louisville, 580 South Preston Street, Delia Baxter

Building, Room 404B, Louisville, KY 40202, USA

Full list of author information is available at the end of the article
} 


\section{Background}

Ambient $\mathrm{PM}_{2.5}$ exposure is tied to cardiovascular disease morbidity and mortality. Furthermore, preexisting cardiovascular disease and diabetes strengthen the link between $\mathrm{PM}_{2.5}$ exposure and acute cardiac events such as arrhythmia, cardiac arrest, and heart failure decompensation [1]. Studies involving direct exposure of animal disease models have added biological plausibility while implicating ANS imbalance, thrombosis, inflammation, and oxidative stress as key mediators. The dose-effect relationship for $\mathrm{PM}_{2.5}$-induced cardiac pathophysiology, its modifying factors, and the underlying mechanisms at real-world exposure levels remain unresolved.

MetS afflicts one third of U.S. adults and is a cluster of at least three of the following risk factors-systolic/ diastolic blood pressure (BP) $\geq 130 / 85 \mathrm{mmHg}$, elevated triglycerides, high fasting glucose, abdominal obesity, and low circulating high density lipoprotein [2]. In MetS subjects researchers have found exaggerated cardiovascular inflammation [3] as well as increased BP and altered heart rate variability (HRV) in association with moderate increases in $\mathrm{PM}_{2.5}$, suggesting pathogenic sympathetic nervous system dominance, a state of enhanced sympathetic influence relative to opposing parasympathetic influences over the cardiovascular system $[4,5]$.

In contrast, $\mathrm{PM}_{2.5}$ exposure at levels beyond U.S. extremes $\left(356 \mu \mathrm{g} / \mathrm{m}^{3}\right)$ in a rat model of MetS decreased $\mathrm{BP}$ and heart rate while increasing HRV, suggesting relative vagal dominance and significantly diverging from the sympatho-excitatory effects of $\mathrm{PM}_{2.5}$ in normal dietfed rats at similar exposure levels [6]. Yet, $\mathrm{PM}_{2.5}$-exposed MetS rats had enhanced epicardial adipose tissue inflammation and oxidative stress compared to normal diet $\mathrm{PM}_{2.5}$-exposed rats [7]. Given recent findings that preexisting cardiometabolic risk factors may not enhance the association between $\mathrm{PM}_{2.5}$ and cardiovascular mortality in humans [8], it remains unclear if and how MetS might actually alter susceptibility to $\mathrm{PM}_{2.5}$ exposure at near-ambient levels. To further explore whether MetS increases susceptibility to $\mathrm{PM}_{2.5}$, we investigated the pathophysiologic effects of repeated exposure to trafficderived $\mathrm{PM}_{2.5}$ at ambient levels in a rat model of MetS characterized by hypertension, hypertriglyceridemia, hyperglycemia, and insulin resistance induced by 8 -week dietary fructose supplementation $[6,9,10]$. We hypothesized repeated exposure to traffic-derived $\mathrm{PM}_{2.5}$ would cause cardiovascular dysfunction in MetS rats distinct from similarly-exposed ND rats. We analyzed arterial pressure and electrocardiograms (ECG) continuously for changes in HRV, cardiac arrhythmia, and spontaneous BRS over a three-week exposure to either FA or $\mathrm{PM}_{2.5}$ from an urban highway tunnel.

\section{Methods}

\section{Animals}

Adult male Sprague Dawley (SD) rats (250-300 g; Taconic Farms Inc., Rennselaer, NY) were housed and treated in accordance with National Institute of Health guidelines for the care and use of laboratory animals. All protocols were approved by the Harvard Medical Area Institutional Animal Care and Use Committee. Normal diet (ND; irradiated PicoLab Rodent Diet 20 5053, Lab Diet, St. Louis, MO) rats were catheterized in the descending abdominal aorta with BP telemeters $(n=8$; DataSciences International, St. Paul, MN, PAC-40) whereas high fructose diet $(\mathrm{HFrD})$ rats were implanted with aortic BP + ECG telemeters in a Lead II configuration ( $n=12$, DSI C50-PXT) at Taconic by trained surgical staff and shipped two weeks later to our mobile laboratory described previously [11]. We previously characterized effects of $\mathrm{P}+\mathrm{SOA}$ exposure in these NDfed rats on $\mathrm{BP}$ and heart rate (HR) [12] and respiratory patterns [13]. Here, we used the same exposure procedures to compare effects of $\mathrm{P}+\mathrm{SOA}$ on a rat MetS model to these ND-fed rats with more advanced endpoints, including HRV, BRS, and BP indices of cardiac performance, with additional ECG analyses in MetS rats. SD rats fed an 8-week $60 \%$ fructose diet (HFrD) bear several clinical features of MetS and thus provide a useful animal model of this syndrome in humans. The MetS group $(n=12)$ received HFrD $(60 \%$ fructose by mass; TD.89247, Harlan Laboratories, Madison, WI) for 8 weeks prior to and throughout inhalation exposure. At the conclusion of the exposure study, blood was collected from MetS rats, centrifuged for serum, aliquoted, stored at $-80{ }^{\circ} \mathrm{C}$, and subsequently analyzed for serum glucose by spectrophotometry at IDEXX Laboratories, Inc. (North Grafton, MA, USA) on an Olympus 5400 chemical analyzer.

\section{Particulate exposure}

We applied two inhalation exposure controls-a 5-h HEPA-filtered air (FA) baseline in ND and MetS rats, and FA groups for each diet. After two 2-h FA exposure acclimations over two days, and a 5-h baseline, MetS $(n=12 ; 127$ days old $)$ and ND $(n=8 ; 100$ days old $)$ rats were assigned evenly and randomly (by weight) for exposure to $\mathrm{FA}$ or combined primary traffic $\mathrm{PM}_{2.5}$ $(<2.5 \mu \mathrm{m}$ aerodynamic diameter $)$ and photochemicallyderived secondary organic aerosols $(\mathrm{P}+\mathrm{SOA})$ from a major northeastern U.S. traffic tunnel plenum for 12 days, 5 h/day, 4 days/week over 3 weeks. Exposure tubes were maintained at $1.5 \mathrm{~L} / \mathrm{min}$ continuous air flow and monitored with plethysmographic transducers (Buxco Electronics, Wilmington, NC) as previously described along with the exposure system [11, 13]. Aerosol was oxidized in a photochemical reaction chamber with 
enough ozone $\left(\mathrm{O}_{3}\right)$ added to titrate vehicular nitric oxide (NO) exhaust and expedite stable secondary particulate generation [14]. After a 4-h residence, aerosol was delivered continuously via two parallel denuders [15] - reducing gaseous pollutant concentrations by $80-90 \%$ - to animal exposure tubes. ND and MetS rats received inhalation exposures in August 2011 and October 2012, respectively. Particle size distribution and concentrations were measured using a scanning mobility particle sizer (SMPS Model 3934, TSI Inc., Shoreview, MN) and a condensation particle counter (CPC Model 3785, TSI). We measured $\mathrm{O}_{3}$ by UV photometry (2B Technologies Inc., Boulder, $\mathrm{CO}$ ), $\mathrm{NO}$ and nitrogen oxides (NOx) by chemiluminescence (Model 42C, Thermo Scientific, Waltham, MA), and carbon monoxide (CO) by infrared absorbance (Model 48, Thermo).

\section{ECG and BP analyses}

For time-series data (except non-normal arrhythmia counts), each rat's change from its own baseline ("delta") was calculated on each exposure day. ECG and BP waveforms were continuously collected during exposure and analyzed in 5-min segments. ECG morphology and HRV were derived using ecgAuto, v3.3 (Emka Technologies, Paris, France) and a library of 199 representative beats with configurations previously described for low frequency (LF) and high frequency (HF) [16]. Time-domain measures included root mean square of successive differences (RMSSD), standard deviation of normal interbeat intervals (SDNN), and coefficient of variation $(\mathrm{CV})-$ ratenormalized SDNN. Time domain parameters for ND rats were generated from systolic pressure peak intervals identified by ecgAuto-an approach we validated in air and $\mathrm{PM}_{2.5}$-exposed MetS rats (Additional file 1: Table S2). To control for atrial premature beats (APBs), we removed inter-beat intervals shortened by $>18 \%$ from the average of 3 preceding and subsequent intervals similar to human studies $[17,18]$. Baseline data were also analyzed by nonlinear HRV methods (Additional file 1: Tables S3 and S4). We classified arrhythmias in MetS rats by treatment-blind ECG inspection, verification in BP, and confirmation by a second investigator using previously described criteria [19] for all but APBs ( $>18 \%$ RR shortening vs. neighboring 6 RRs, normal PR) and non-conducted APBs (ncAPB; dropped QRS and $>18 \%$ PP shortening vs. prior 4 PPs). Non-conducted P-wave arrhythmias were differentiated as either ncAPB (premature P wave unfollowed by a QRS), second degree AV block Mobitz I events (a P at a normal interval from the prior $\mathrm{P}$ and accompanied by $\mathrm{a} \geq 2$-fold increase in RR interval but preceded by PR interval prolongation within the prior 4 normal QRS complexes or a PR interval shortening in the first conducted QRS complex thereafter), second degree AV block Mobitz II events (un-prolonged PR over the four prior QRS complexes, normal PR interval in the first conducted QRS complex thereafter), or advanced AV block (same criteria as Mobitz II, but RR $\geq 3$-fold increase). ECGs on all exposure days were examined for all arrhythmias except APBs, which were identified on half of exposure days selected at random (Baseline and days 1, 4, 6, 8, 11, 12). BP was analyzed as described previously [20], including aortic $d P / d t_{\max }$, an indirect index of left ventricular contractility and predictor of death and decompensation in heart failure patients [21, 22]. After exclusion of ectopic beats, we calculated spontaneous BRS slope by the "sequence method" [23] in ecgAUTO, selecting inter-beat interval series $(\geq 3)$ in which successive pairs of systolic peaks and subsequent beat intervals varied $\geq 0.50 \mathrm{mmHg}$ and $\geq 0.30 \mathrm{~ms}$, respectively, with a correlation $\geq 0.50$. ECG morphology was analyzed as described [19], adding minimum ST slope (S min. Slope, during initial $1.5 \mathrm{~ms}$ after S) and ST amplitude (ST amp, mean at 2-4 ms after S). QT was rate-corrected by Fridericia formula or, only where specifically indicated, Bazzett's formula.

Time series physiologic data are presented as change from baseline to allow consistent comparison to reported effects of much higher $\mathrm{PM}_{2.5}$ exposures in this same model of high fructose diet-induced MetS [6]. For time-series data where possible, daily differences in deltas between $\mathrm{P}+\mathrm{SOA}$ and FA groups receiving the same diet are presented as single daily values to facilitate comparison to a prior companion study involving MetS rats and higher $\mathrm{PM}_{2.5}$ exposure concentrations [6].

\section{Ventilatory durations}

We analyzed whole body plethysmographic data from MetS rats as previously detailed [13] to provide daily averages of inspiratory, expiratory, and total times $\left(\mathrm{T}_{\mathrm{I}}\right.$, $\mathrm{T}_{\mathrm{E}}$, and $\mathrm{T}_{\mathrm{T}}$ ), respiratory frequency $(f)$, and respiratory pause from continuous 10-min averages.

\section{Statistics}

Baseline data were compared between diets by student's two-tailed t-test (Microsoft Excel), with $P<0.05$ considered significant and all other analyses performed in SAS 9.3 (Cary, NC). We analyzed time-series deltas (each animal's change during exposure from its own value at baseline) with linear mixed effects models (PROC MIXED) for daily or overall inhalant effects while controlling for day and selecting a random effects structure using AIC best fit criteria. Given their non-normality and longitudinality, we analyzed arrhythmia counts via generalized estimating equation (PROC GENMOD) as number of events per 5-h exposure day, including each rat's baseline as its own intercept and assuming a Poisson distribution and exchangeable correlation structure. PROC REG was used to compare all BRS or arrhythmia values to physiologic parameters (simple linear regression) or pollutant concentrations (partial regression accounting for group). 


\section{Results}

\section{Diet effects}

During baseline, MetS rats had increased BP, SDNN, and aortic $\mathrm{dP} / \mathrm{dt}_{\max }$ relative to control-diet rats but no difference in BRS slope (Table 1). Additional HRV analyses confirmed our initial observations (Additional file 1: Table S3 and Table S4). Eight-week HFrD corresponded with a $152-\mathrm{g}$ increase in mean body mass (311 \pm 5 to $463 \pm 10 \mathrm{~g}$ ), equivalent to body mass change in normal diet SD rats over the same time as previously noted [7]. At the conclusion of the study, air-exposed MetS rats had hyperglycemia (mean \pm SEM: $243.8 \pm 18.4 \mathrm{mg} / \mathrm{dL}$ ) relative to a historic range for normal diet-fed male Sprague Dawley rats at a corresponding age of 20 weeks (50$135 \mathrm{mg} / \mathrm{dL}$ ), with no additional effect of $\mathrm{P}+\mathrm{SOA}$.

\section{$\mathrm{P}+$ SOA exposure}

Overall, MetS-P + SOA rats received $\mathrm{PM}_{2.5}$ at concentrations $64 \%$ lower by mass and $27 \%$ lower by count than ND-P + SOA rats (Table 2). Concentrations remained consistent throughout the entire exposure regimen (Additional file 1: Fig. S1). By count, approximately half of particulates were ultrafine for MetS-P + SOA rats and slightly fewer than half were ultrafine for ND-P + SOA rats. Additional information regarding $\mathrm{P}+\mathrm{SOA}$ composition (organic carbon, elemental carbon, nitrate, and sulfate fractions) is presented in Additional file 1: Table S1.

\section{Autonomic balance}

$\mathrm{P}+$ SOA significantly altered HRV in MetS rats, decreasing RMSSD delta by $1.31 \mathrm{~ms}$ overall (Table 3 ) and on nearly half of exposure days (Fig. 1) relative to MetS-FA rats. In contrast, $\mathrm{P}+\mathrm{SOA}$ did not alter time domain HRV parameters in ND rats overall and only significantly decreased SDNN delta on day 1 relative to ND-FA rats.

Table 1 Baseline cardiovascular physiology in control-fed $(n=8)$ and MetS $(n=12)$ rats

\begin{tabular}{lllll}
\hline & \multicolumn{2}{c}{$\mathrm{ND}$} & \multicolumn{2}{c}{ MetS } \\
\hline Systolic BP (mmHg) & 121 & \pm 1.9 & 143.9 & $\pm 5.8^{* * *}$ \\
Diastolic BP (mmHg) & 86.6 & \pm 1.3 & 95.7 & $\pm 4.3^{*}$ \\
$d P / d t_{\text {max }}(\mathrm{mmHg} / \mathrm{s})$ & 1487 & \pm 49 & 2093 & $\pm 105^{* * *}$ \\
Heart Rate (beats/min) & 333.3 & \pm 5.1 & 328.6 & \pm 5.8 \\
BRS slope (ms/mmHg) & 1.81 & \pm 0.28 & 1.65 & \pm 0.23 \\
RMSSD (ms) & 4.1 & \pm 0.34 & 5.05 & \pm 0.68 \\
SDNN (ms) & 6.85 & \pm 0.47 & 8.62 & $\pm 0.50^{*}$ \\
HF (ms $\left.{ }^{2}\right)^{\text {a }}$ & 1.37 & \pm 0.22 & 2.55 & \pm 0.73 \\
LF (ms $\left.{ }^{2}\right)^{\text {a }}$ & 0.90 & \pm 0.20 & 0.98 & \pm 0.35 \\
LF/HF† & 0.64 & \pm 0.05 & 0.50 & \pm 0.06 \\
\hline
\end{tabular}

Means \pm SE from baseline FA exposure. ${ }^{a}$ indicates values from ECG + BP telemetered ND rats under the same baseline monitoring and FA conditions $(n=14) .{ }^{*}$ and ${ }^{* * *}$ indicate $P<0.05$ and $<0.001$, respectively
Table 2 Characteristics of $\mathrm{P}+\mathrm{SOA}$ exposure

\begin{tabular}{lrlrl}
\hline Pollutant & \multicolumn{2}{c}{ ND } & \multicolumn{2}{c}{ MetS } \\
\hline $\mathrm{PM}_{2.5}$ Mass $\left(\mu \mathrm{g} / \mathrm{m}^{3}\right)$ & 56.3 & \pm 1.2 & 20.4 & \pm 0.9 \\
$\mathrm{PM}_{2.5}$ Count (thousand $\left./ \mathrm{cm}^{3}\right)$ & 9.0 & \pm 0.2 & 6.6 & \pm 0.2 \\
$\mathrm{PM}_{2.5}$ MMD $(\mathrm{nm})$ & 297.0 & \pm 6 & 262.7 & \pm 2 \\
$\mathrm{PM}_{2.5}$ CMD $(\mathrm{nm})$ & 135.0 & \pm 2 & 95.2 & \pm 2 \\
$\mathrm{NO}(\mathrm{ppb})$ & 1.0 & \pm 0 & 3.2 & \pm 1.2 \\
$\mathrm{NO}_{x}(\mathrm{ppb})$ & 2.6 & \pm 0.5 & 11.3 & \pm 1 \\
$\mathrm{O}_{3}(\mathrm{ppb})$ & - & - & 22.7 & \pm 2.1 \\
$\mathrm{CO}(\mathrm{ppm})$ & - & - & 1.0 & \pm 0 \\
\hline
\end{tabular}

Means $\pm \mathrm{SE}$ over entire 12-day exposure period. $\mathrm{PM}_{2.5} \mathrm{MMD}$ and $\mathrm{CMD}$ denote mass and count median diameters \pm geometric standard deviation. $\mathrm{P}+\mathrm{SOA}$ exposure of ND rats applied the same parallel gas denuders as for MetS, but $\mathrm{CO}$ and $\mathrm{O}_{3}$ were not measured. FA was not monitored

\section{Hemodynamics}

In ND rats, $\mathrm{P}+\mathrm{SOA}$ overall significantly increased systolic pressure, aortic $d p / d t_{\text {max }}$, and pulse pressure (PP) deltas vs. FA (Table 3). Conversely, $\mathrm{P}+\mathrm{SOA}$ exposure in MetS rats decreased $d P / d t_{\text {max }}$ and PP deltas overall vs. both the MetSFA and ND-P + SOA groups, and P + SOA exposure decreased rate pressure product delta in MetS rats relative to $\mathrm{P}+\mathrm{SOA}$-exposed ND rats. $\mathrm{P}+\mathrm{SOA}$ only affected MetS rats' daily pressures on day 11 via an increase in PP (vs. MetS-FA), whereas it increased systolic, diastolic, and/or PP deltas among ND rats relative to the ND-FA group on the first eight exposure days but decreased diastolic pressure on day 11 (Fig. 2). On many of the exposure days, MetS$\mathrm{P}+\mathrm{SOA}$ rats also significantly diverged from ND-P + SOA rats in aortic $d P / d t_{\text {max }}$ (days 1-10) and PP (days 3-9) deltas. BP did not associate with HRV in either strain (Table 4).

\section{Baroreflexes}

MetS-P + SOA rats had decreased BRS slope delta vs. both MetS-FA rats and ND-P + SOA rats on three exposure days (Fig. 2). As well, MetS-P + SOA rats had decreased BRS slope delta relative to ND-P + SOA rats overall $(-0.47 \mathrm{~ms} / \mathrm{mmHg}, P<0.01)$ and a trend of similar effect vs. MetS-FA rats $(-0.34 \mathrm{~ms} / \mathrm{mmHg}, P=0.0946)$. Among all MetS rats, BRS slope delta correlated positively with HRV deltas and inversely with $\mathrm{HR}, \mathrm{PP}$, and $d P / d t_{\text {max }}$ deltas (Table 5), all $P<0.0001$ ) as well as rate-pressure product $(P<0.001)$. Similarly, in ND rats BRS slope delta positively correlated with $\mathrm{CV}$ and inversely correlated with PP and $d P / d t_{\text {max }}$ deltas, consistent with autonomic modulation of HRV, cardiac inotropy, and baroreflexes.

\section{Arrhythmia and ECG}

On exposure day 4 there was a four-fold increase in second degree Atrioventricular (AV) block Mobitz type II arrhythmias in MetS-P + SOA rats compared to MetS-FA rats (Fig. 3), corresponding with a significant decline in PR interval delta (Fig. 4). These arrhythmias, which are 
Table 3 Overall Effects of $\mathrm{P}+\mathrm{SOA}$ exposure on ND and MetS rats

\begin{tabular}{|c|c|c|c|c|c|c|}
\hline & & & & & & MetS vs. ND \\
\hline & & effect & $P$ & effect & $P$ & $P$ \\
\hline & Diastolic Pressure $(\mathrm{mmHg})$ & -0.45 & 0.874 & -0.532 & 0.830 & 0.1073 \\
\hline & Systolic Pressure (mmHg) & $2.97^{*}$ & 0.044 & -1.26 & 0.692 & $0.021^{*}$ \\
\hline & Aortic $d P / d t_{\max }(\mathrm{mmHg} / \mathrm{ms})$ & $157^{*}$ & 0.013 & $-109^{*}$ & 0.007 & $<0.001^{*}$ \\
\hline & Pulse Pressure $(\mathrm{mmHg})$ & $3.26^{*}$ & 0.020 & $-1.97^{*}$ & 0.035 & $<0.001^{*}$ \\
\hline & Rate $\times$ Pressure $\left(\mathrm{BPM}^{*} \mathrm{mmHg} / 1000\right)$ & 0.098 & 0.927 & -0.860 & 0.654 & $0.05^{*}$ \\
\hline & Heart Rate (BPM) & 4.70 & 0.660 & -1.74 & 0.814 & 0.458 \\
\hline & $\mathrm{BRS}(\mathrm{ms} / \mathrm{mmHg})$ & 0.167 & 0.807 & -0.338 & 0.095 & $0.009^{*}$ \\
\hline HRV & RMSSD (ms) & -0.023 & 0.946 & $-1.31^{*}$ & 0.027 & 0.076 \\
\hline & SDNN (ms) & -0.101 & 0.855 & -0.245 & 0.729 & 0.913 \\
\hline & $\mathrm{HF}\left(\mathrm{ms}^{2}\right)$ & & & -0.921 & 0.068 & \\
\hline & $\operatorname{LF}\left(\mathrm{ms}^{2}\right)$ & & & 0.116 & 0.630 & \\
\hline ECG & PR Interval (ms) & & & $-1.27^{*}$ & 0.036 & \\
\hline & QTc Interval (ms) & & & $-2.16^{*}$ & 0.025 & \\
\hline
\end{tabular}

Overall differences between diet-matched P + SOA- and FA-exposed groups in cardiovascular physiologic deltas from baseline or between opposing diets with exposure to $P+$ SOA (right column, significance only). *indicates $P<0.05$ by linear mixed model analysis

The italic font indicated significant differences

relatively rare, occurred in half of the $\mathrm{P}+\mathrm{SOA}$-exposed rats on day 4. MetS-P + SOA rats had decreased QTc and PR interval deltas overall (Table 3 and Fig. 4). Interestingly, two $\mathrm{ND}$ rats exposed to $\mathrm{P}+\mathrm{SOA}$ had paroxysmal tachycardia (HR $>500$ beats $/ \mathrm{min}$ ) of undiscernible anatomical origin, with one sustained through day eight's exposure and the other for twelve minutes on day 7. Among Mets rats, HRV, PR, and QTc inversely correlated with AV block Mobitz II arrhythmias, whereas these markers positively correlated with AV block Mobitz I, indicating potentially divergent autonomic origins (all $P<0.05$; Additional file 1: Table S5). Second degree AV block Mobitz I events are a common benign consequence of parasympathetic activation-mediated vagal inhibition of the AV node, whereas Mobitz II events are a clinical indication for pacemaker implantation due to underlying pathology, including but not limited to potential inflammation and/or fibrosis.

\section{Ventilatory parameters}

$\mathrm{PM}_{2.5}$ increased $f$ by 11.2 breaths per minute and decreased $T_{E}$ and $T_{T}$ by $33.2 \mathrm{~ms}$ and $68.5 \mathrm{~ms}$, respectively, in MetS rats overall and had similar effects on several individual days without affecting $\mathrm{T}_{\mathrm{I}}$ or Pause (Fig. 5). Among MetS rats $f$ and $\mathrm{T}_{\mathrm{T}}$ deltas correlated with RMSSD and HF deltas, whereas $T_{I}$ and Pause deltas correlated with SDNN delta (Additional file 1: Table S6).
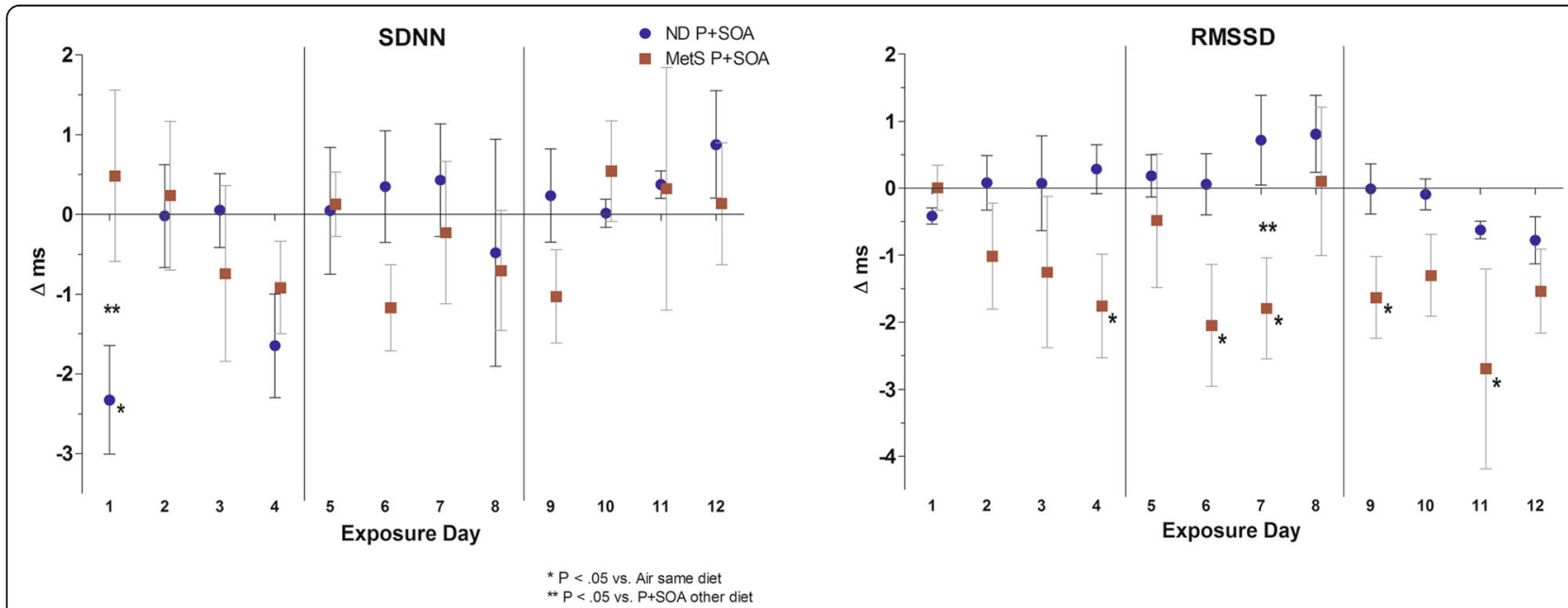

Fig. 1 Daily time-domain HRV in ND and MetS rats. Values represent mean daily difference from diet-matched air-exposed group in change from baseline ( \pm SE, $n=4-6 /$ group) ${ }^{*}-P<0.05$ vs. Air same diet. ${ }^{*}-P<0.05$ vs. $P+S O A$ other diet. Vertical lines indicate weekends 


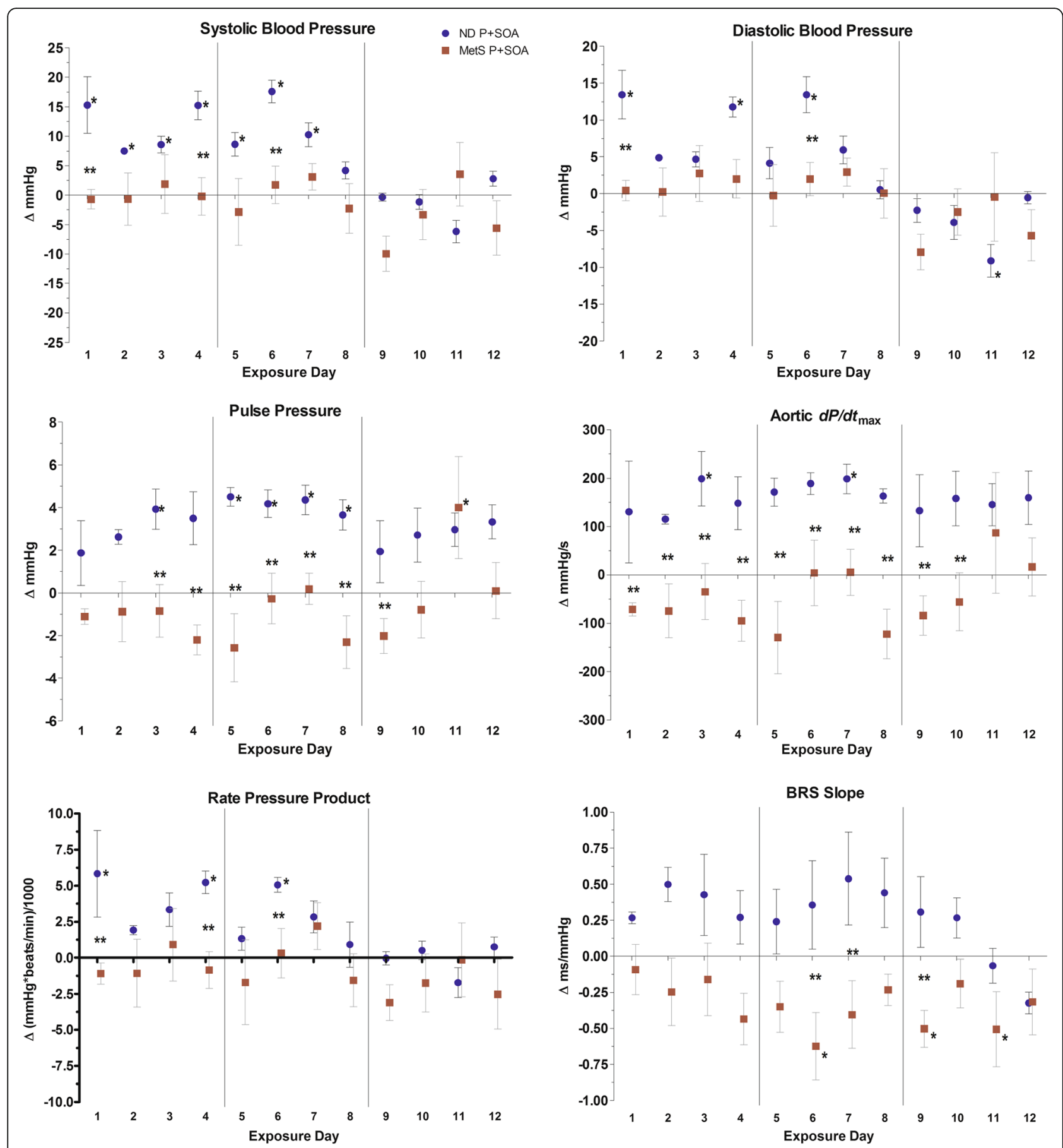

Fig. 2 Hemodynamics in ND and MetS rats. Values represent mean daily difference from diet-matched air-exposed group in change from baseline ( $\pm \mathrm{SE}, n=4-6 /$ group). ${ }^{*}-\mathrm{P}<0.05$ vs. Air same diet. ${ }^{* *}-\mathrm{P}<0.05$ vs. $\mathrm{P}+\mathrm{SOA}$ other diet. Vertical lines indicate weekends.

\section{Predictors of arrhythmia}

BRS slope inversely correlated with half of arrhythmia types, including AV block Mobitz type II, which itself also inversely correlated with most HRV parameters (including RMSSD), respiratory pause, PR, QTc, and ST amplitude (an index of myocardial ischemia) (Additional file 1: Table S5). In contrast, Mobitz type I AV block correlated positively with most of the aforementioned parameters, affirming its likely vagal origins and indicating divergent etiologies between Mobitz I and Mobitz II AV block events. Accordingly, HRV index of relative sympathetic influence (LF/HF) positively correlated with AV block Mobitz II events in MetS rats. 
Table 4 Relationship between HRV and blood pressure changes from baseline in ND and MetS rats

\begin{tabular}{lllllllll}
\hline & & \multicolumn{3}{c}{$\Delta$ SBP } & \multicolumn{3}{c}{$\Delta$ DBP } & \multicolumn{3}{c}{$\Delta$ MBP } \\
& & $r$ & $p$-value & $r$ & $p$-value & $r$ & $p$-value \\
\hline ND rats & $\Delta$ RMSSD & 0.05 & 0.63 & 0.15 & 0.16 & 0.11 & 0.31 \\
& $\Delta$ SDNN & 0.04 & 0.71 & -0.08 & 0.48 & -0.01 & 0.94 \\
\multirow{4}{*}{ MetS rats } & $\Delta$ RMSSD & -0.06 & 0.51 & 0.00 & 0.99 & -0.02 & 0.83 \\
& $\Delta$ SDNN & 0.05 & 0.58 & 0.10 & 0.23 & 0.07 & 0.39 \\
\hline
\end{tabular}

Pearson correlation coefficients and $P$-values for linear regression between HRV delta and various aortic pressure deltas among all MetS and ND rats during exposure periods

We examined respiratory flow waves of MetS rats on half of exposure days (days 1, 4, 6, 8, 11, and 12) for ventilatory rhythm disturbances (abrupt braking, apnea, or tachypnea) in the $3 \mathrm{~s}$ before arrhythmias to determine if these bradyarrhythmias immediately followed indications of vagal afferent-mediated irritant reflexes (characterized by tachypnea and respiratory braking with C-fiber activation [24]). Most Mobitz II events immediately followed ventilatory rhythm disturbances regardless of $\mathrm{P}+\mathrm{SOA}$ or filtered air exposure; however, $\mathrm{P}+\mathrm{SOA}$ exposure unexpectedly corresponded with two-fold more Mobitz II events preceded by undisturbed respiratory rhythm (36\% vs. 19\% of events relative to FA) and equivalent respiratory disturbanceassociated Mobitz II events. When Mobitz II events significantly increased in $\mathrm{P}+\mathrm{SOA}$-exposed rats (day 4 ), they occurred even more disproportionately with normal respiratory waves $(43 \%$, vs. $9 \%$ in FA), accounting entirely for the group difference since ventilatory rhythm disturbance-associated events remained equal between groups.

\section{Discussion}

We found in a HFrD-fed rat model of MetS that repeated traffic-derived $\mathrm{PM}_{2.5}$ exposure at environmentally relevant concentrations decreases relative vagal influence over cardiovascular function, diminishes baroreflexes to arterial pressure fluctuations, and alters electrophysiology concomitant with increased spontaneous arrhythmia. In contrast, normal diet rats showed minimal effects of $\mathrm{PM}_{2.5}$ on BRS and HRV while having consistent hypertensive responses in the first seven days of exposure that vanished thereafter. The declines in HRV and BRS and their association with increasing arrhythmia among MetS rats suggest repeat exposure to ambient $\mathrm{PM}_{2.5}$ impairs autonomic regulation of cardiovascular homeostasis especially among those with cardiometabolic disorder. $\mathrm{P}+$ SOA also diminished SDNN in normal-fed rats, but this occurred only on day 1 of exposure. The lack of recurrence of these effects in ND rats suggests that normal animals may acutely respond similarly to initial PM exposure
Table 5 Correlation between BRS and physiologic markers, $\mathrm{PM}_{2.5}$ concentrations, or gaseous components

\begin{tabular}{|c|c|c|}
\hline & ND & MetS \\
\hline HR (beats/min) & $0.23^{*}$ & $-0.28^{* *}$ \\
\hline RMSSD (ms) & 0.18 & $0.71^{* * *}$ \\
\hline SDNN (ms) & 0.19 & $0.49^{* * *}$ \\
\hline CV & $0.27^{* *}$ & $0.40^{* * *}$ \\
\hline pNN15 & - & $0.59^{* * *}$ \\
\hline $\mathrm{HF}\left(\mathrm{ms}^{2}\right)$ & - & $0.58^{* * *}$ \\
\hline $\operatorname{LF}\left(m s^{2}\right)$ & - & $0.71^{* * *}$ \\
\hline $\mathrm{LF} / \mathrm{HF}$ & - & -0.13 \\
\hline $\mathrm{SBP}(\mathrm{mmHg})$ & 0.00 & -0.16 \\
\hline $\mathrm{DBP}(\mathrm{mmHg})$ & $0.28^{* *}$ & -0.08 \\
\hline $\mathrm{PP}(\mathrm{mmHg})$ & $-0.49^{* * *}$ & $-0.32^{* * *}$ \\
\hline$d P / d t_{\max }(\mathrm{mmHg} / \mathrm{s})$ & $-0.41^{* * *}$ & $-0.35^{* * *}$ \\
\hline rate $\times \mathrm{P}(\mathrm{BPM} \times \mathrm{mmHg})$ & -0.06 & $-0.27^{* *}$ \\
\hline PR (ms) & - & $0.27^{* *}$ \\
\hline $\mathrm{QTcB}(\mathrm{ms})$ & - & $0.32^{* * *}$ \\
\hline QTcF (ms) & - & $0.24^{* *}$ \\
\hline QTe (ms) & - & -0.11 \\
\hline $\mathrm{S} \min$. Slope $(\mathrm{mV} \times \mathrm{ms})$ & - & 0.01 \\
\hline ST amp (mV) & - & 0.13 \\
\hline TpTe (ms) & - & $0.17^{*}$ \\
\hline$f$ (breaths/min) & - & $-0.41^{* * *}$ \\
\hline$T_{1}(\mathrm{~ms})$ & - & 0.07 \\
\hline$T_{E}(\mathrm{~ms})$ & - & $0.36^{* * *}$ \\
\hline$T_{T}(\mathrm{~ms})$ & - & $0.35^{* * *}$ \\
\hline Pause (s) & - & 0.14 \\
\hline $\mathrm{PM}_{2.5}$ mass $\left(\mu \mathrm{g} / \mathrm{m}^{3}\right)$ & -0.04 & -0.11 \\
\hline $\mathrm{PM}_{2.5}$ count $\left(\# / \mathrm{m}^{3}\right)$ & -0.03 & -0.05 \\
\hline NO (ppb) & 0.00 & -0.09 \\
\hline $\mathrm{NO}_{\times}(\mathrm{ppb})$ & -0.01 & -0.12 \\
\hline $\mathrm{O}_{3}(\mathrm{ppb})$ & - & 0.03 \\
\hline CO (ppm) & - & -0.04 \\
\hline
\end{tabular}

Pearson correlation coefficients for linear regression between BRS slope and various physiologic and exposure endpoints in MetS and ND-fed rats over the course of the entire exposure period, including both filtered air- and P + SOAexposed animals. Pearson partial correlation was conducted for air pollutant concentrations. ${ }^{*}{ }^{* *}$, and ${ }^{* * *}$ indicate $P<0.05,0.01$, and 0.001 , respectively. Dash alone indicates parameter was not analyzed

but may thereafter mount compensatory adaptations to preempt subsequent effects. To our knowledge, this is the first demonstration that controlled exposure to trafficderived $\mathrm{PM}_{2.5}$ at ambient levels impairs baroreflexes and causes spontaneous arrhythmia in conjunction with depressed HRV. Collectively, our observations indicate that MetS increases susceptibility to the adverse effects of ambient-level $\mathrm{PM}_{2.5}$, likely via ANS imbalance. 


\section{AV Block Mobitz Type II}

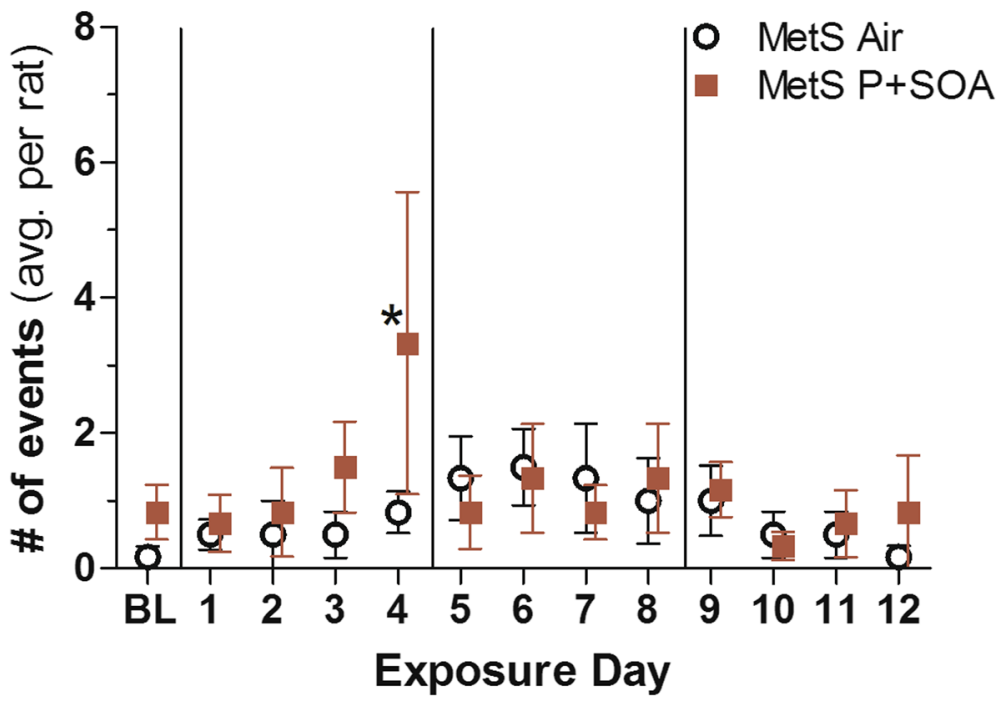

Fig. $3 \mathrm{P}+\mathrm{SOA}$ exposure increased Atrioventricular Block Mobitz Type II arrhythmias in MetS rats on specific days relative to Air-control. Data are expressed as means \pm SE $(N=6 /$ group)

Overall, our findings suggest MetS increases cardiovascular susceptibility to $\mathrm{PM}_{2.5}$ via sympathetic dominance, indicated by decreases in RMSSD, spontaneous BRS, and PR interval. HRV indicates autonomic regulation of cardiac rhythm, and decreases in most HRV parameters (e.g., RMSSD, SDNN, HF) indicate increased sympathetic influence. Unlike healthy, ND-fed rats, HFrD-fed rats with MetS responded to $\mathrm{PM}_{2.5}$ exposure with sustained decreases in HRV and BRS, as well as tachypnea, and QTc- and PR-shortening, all of which are tied to sympathetic dominance [25-28]. In fact, we found significant correlations between HRV and tachypnea suggesting an important coupling between $\mathrm{PM}_{2.5}$-induced alterations in respiration and cardiac autonomic imbalance. RMSSD derives in part from respiratory sinus arrhythmia, involving the acceleration of pacemaker nodal rhythm via an abrupt parasympathetic withdrawal during stimulation of pulmonary stretch receptors [29]. As such, decreases in RMSSD may derive from (i) decreased stimulation of respiratory stretch receptors, (ii) sympathetic antagonism of parasympathetic-mediated respiratory sinus arrhythmia [30, 31], and/or (iii) impaired integrity of vagal efferent neurons [32].

In ND rats $\mathrm{P}+\mathrm{SOA}$ exposure had notable hypertensive effects that we have previously discussed in detail [12]. The absence of a hypertensive effect of $\mathrm{P}+\mathrm{SOA}$ exposure in MetS rats may stem from a number of factors, including dose dependency of $\mathrm{P}+\mathrm{SOA}$. MetS rats were exposed to lower $\mathrm{P}+\mathrm{SOA}$ concentrations than the ND rats, having average $\mathrm{PM}_{2.5}$ mass and count concentrations that were
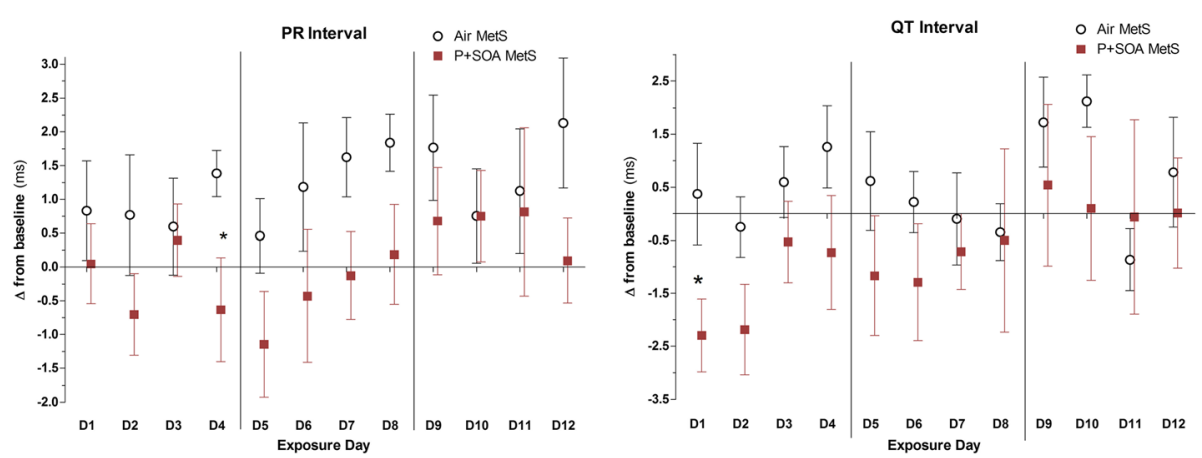

Fig. 4 Daily change in ECG PR and QTc (Fridericia) interval from baseline in MetS rats during exposure to FA (Air) or P + SOA. Values represent group mean of daily change from individual rats' values at baseline ( $\pm \mathrm{SE}, n=6 / \mathrm{group})$. Vertical lines delineate exposure weeks. Asterisk denotes significant difference between time-matched group averages $(P<0.05)$ 


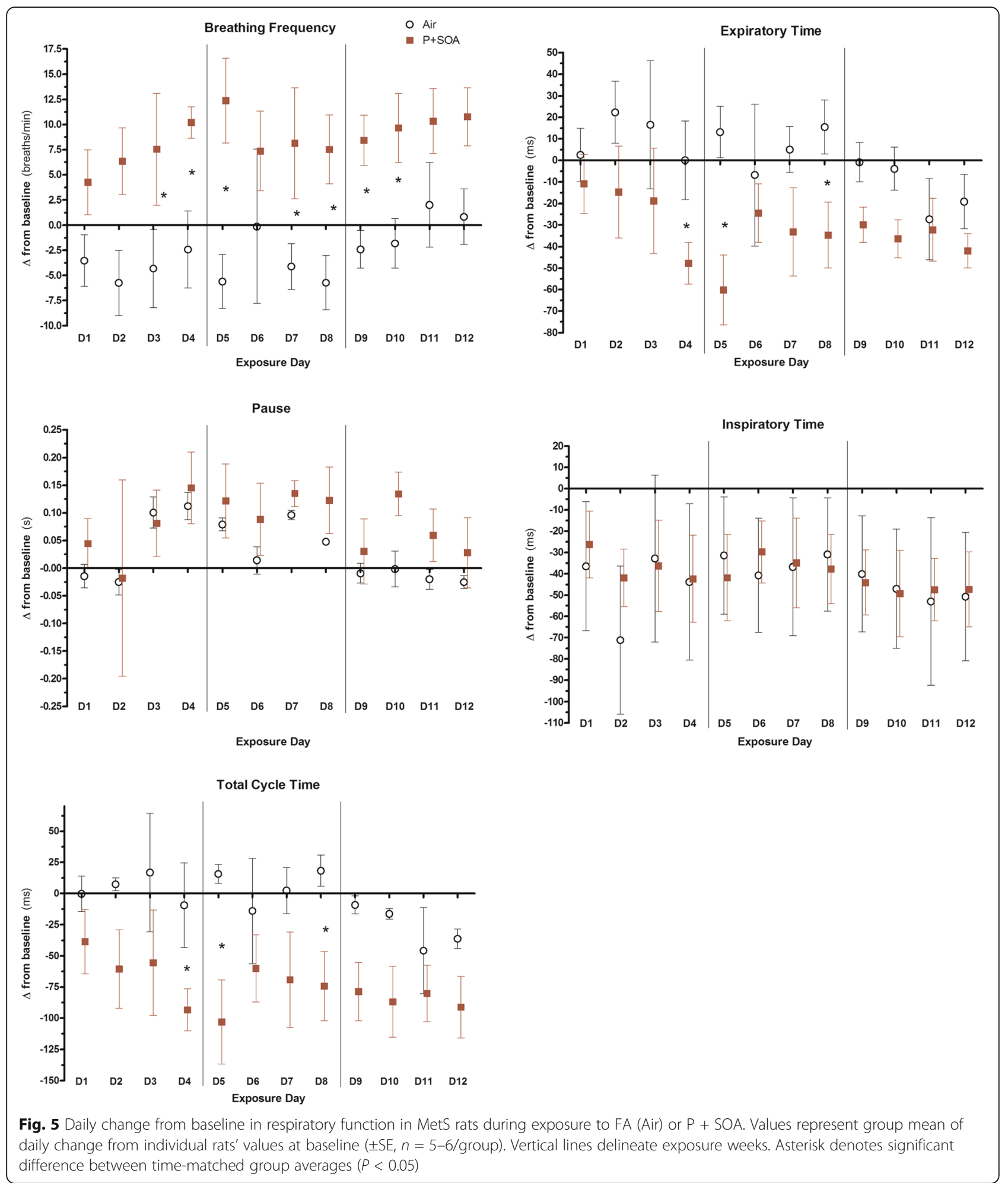

$36 \%$ and $73 \%$ of those that the ND rats received. As well, rats fed a normal diet and having normal blood pressure may have had greater potential for hypertensive responses to $\mathrm{PM}_{2.5}$ simply because the MetS rats already had frank hypertension. Indeed, dietary fructose may have overshadowed any such hypertensive effects of $\mathrm{PM}_{2.5}$ in MetS rats through a common non-autonomic pathway (e.g., renin-angiotensin system activation). Others have revealed evidence that both $\mathrm{PM}_{2.5}$ and high fructose diets induce hypertension through the renin- 
angiotensin system [33, 34]. Similarly suggesting our hemodynamic observations were unrelated to autonomic influences, we observed no statistical associations between changes in HRV and BP in either ND or MetS rats (Table 4). Accordingly, BRS slope also suggested $\mathrm{PM}_{2.5}$ uniquely caused autonomic-associated dysfunction only in MetS rats. The cardiac baroreflex is a negative feedback loop by which arterial pressure receptors relay BP changes to the brain, which inversely tunes heart rate by adjusting parasympathetic tone. Diminished baroreflexes indicate impaired compensatory responses to periodic increases in aortic pressure (and cardiac afterload). Ultimately, this may increase overall cardiac systolic workload and promote heart failure. Our laboratory previously observed in tracheostomized dogs that repeated exposures to much higher $\mathrm{PM}_{2.5}$ levels $\left(358 \mu \mathrm{g} / \mathrm{m}^{3}\right)$ increase BP and BRS, likely in compensation for $\mathrm{PM}_{2.5}$ 's hypertensive effects [35]. Although $\mathrm{PM}_{2.5}$ did not significantly increase BRS in ND rats despite its hypertensive effects, differences in species and exposure traits hinder comparability with this past study. Nevertheless, the decreases in BRS and HRV suggest MetS increases susceptibility to $\mathrm{PM}_{2.5}$-induced cardiovascular dysfunction via the ANS.

Our observations lend further plausibility to the mounting evidence that $\mathrm{PM}_{2.5}$ causes adverse cardiac outcomes through sympathetic dominance [1]. Such effects have been tied to autonomic imbalance and found to either herald or precipitate cardiovascular mortality. La Rovere and colleagues [28] found that depressions in BRS and HRV independently predicted long-term mortality and synergistically foretold a seven-fold increase in mortality rates among myocardial infarction survivors. Spontaneous BRS has also been inversely correlated with mortality and adverse cardiovascular events [23]. As well, low aortic dP/ $\mathrm{dt}_{\max }$ - an index of left ventricular contractility-has been deemed predictive of death and transplantation in heart failure patients [21]. Separately, Mobitz type II AV block arrhythmia often progresses to complete heart block in humans [36] and is considered a high-grade bradyarrhythmia, which others have attributed to one sixth of ambulatory sudden cardiac deaths [37]. Likewise, QT and PR shortening are both established predictors of mortality $[38,39]$. Although others have made similar observations to ours, they have typically involved air pollutants far exceeding ambient concentrations. Hazari and colleagues [40] recently reported acute inhalation of the combustion product acrolein at levels $>1000$-fold [41] traffic-congested urban environments causes strikingly similar effects on BRS, AV block arrhythmia, QT, PR, and HRV. Conversely, we saw effects in MetS rats at $\mathrm{PM}_{2.5}$ levels with a 24 -h average $<1 / 8$ th the daily U.S. Environmental Protection Agency standard (4.3 vs. $\left.35 \mu \mathrm{g} / \mathrm{m}^{3}\right)$.
Short-term ambient $\mathrm{PM}_{2.5}$ exposures have been linked to greater HRV decrements in MetS subjects than in healthy subjects [4] or type 2 diabetics [42]. Yet, controlled exposures (involving five- to ten-fold higher concentrations) provide little evidence that MetS increases autonomic or hemodynamic susceptibility [43, 44]. Using the same fructose-induced MetS rat model as ours, others found that a 9-day CAPs exposure at higher concentrations $\left(356 \mu \mathrm{g} / \mathrm{m}^{3}\right)$ enhanced oxidative stress and inflammation in epicardial adipose tissue [7] but also increased HRV divergent from normal diet rats [6]. Indeed, acute exposure to similarly high $\mathrm{PM}_{2.5}$ concentrations has repeatedly elicited transient parasympathetic dominance in rodent models of cardiovascular disease [45-47]. Such vagal dominance likely stems from pulmonary and airway irritant reflexes that directly inhibit sympathetic neurons, manifesting as increased HRV at high pollutant levels in humans as well [48-50]. Fittingly, Farraj and colleagues [45] recently noted repeated exposure to biodiesel emissions in hypertensive rats decreased HRV at $50 \mu \mathrm{g} / \mathrm{m}^{3}$, had no effect at $150 \mu \mathrm{g} / \mathrm{m}^{3}$, and increased HRV at $500 \mu \mathrm{g} /$ $\mathrm{m}^{3}$. Conversely, central oxidative stress can induce sympathetic dominance [51], and exogenous antioxidants may inhibit $\mathrm{PM}_{2.5}$-induced alterations in HRV [52]. Among MetS individuals exposed to $\mathrm{PM}_{2.5}\left(98 \mu \mathrm{g} / \mathrm{m}^{3}\right)$, only those with compromised antioxidant defenses had decreased HRV [44]. Controlled exposures to lower $\mathrm{PM}_{2.5}$ levels $\left(24-50 \mu \mathrm{g} / \mathrm{m}^{3}\right)$ in diabetic, elderly, overweight, or coronary heart disease subjects can elicit similar decreases in HRV [53-56]. Exposures to ambient ultrafine PM (UFP: 10$100 \mathrm{~nm}$ diameter) and accumulation mode PM (AMP: 100-500 nm diameter) at levels comparable to our study have also been associated with decreased HRV and impaired ventricular repolarization in cardiac rehabilitation patients [57]. Yet the HRV-PM exposure relationship also can invert with beta-adrenergic blockade [56], suggesting that sympathoexcitation may obscure vagal pulmonary irritant reflexes at lower concentrations. Thus, separate dose-dependencies for these two competing autonomic pathways may drive a quasi-sinusoidal relationship between acute exposure and cardiophysiologic responses, varying with susceptibility (e.g., antioxidant status), respiratory deposition site, and particulate size and composition (Fig. 6). In this context, our findings indicate future controlled exposure studies may better elucidate the pathophysiologic effects of $\mathrm{PM}_{2.5}$ through multi-day exposures at real-world levels.

Increased sympathetic tone to the heart promotes arrhythmia, oxidative stress, contractile dysfunction, and eventual cardiac remodeling via distinct molecular pathways [58-60]. Nevertheless, acute sympathetic dominance only alludes to cardiac pathogenesis. In contrast, AV block Mobitz type II arrhythmia is a tangible marker of cardiac instability and a clinical 


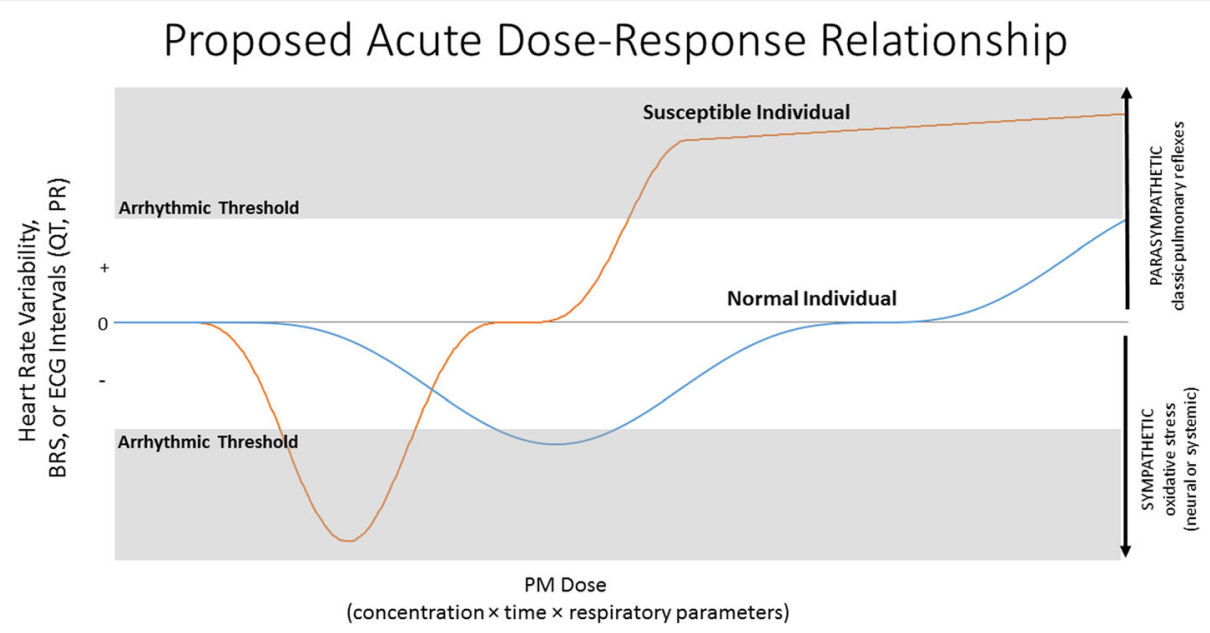

Fig. 6 Proposed relationship between cardiac physiology and acute particulate exposure based on susceptibility (e.g., hypertension, MetS, age, heart failure). With increasing concentration and/or exposure time, parasympathetic reflexes may counteract sympathetic dominance, dependent on antioxidant status, pulmonary clearance, vagal integrity, additional gaseous pollutants, and particulate interaction with irritant receptors

indication for pacemaker implantation. Additionally, HRV and BRS inversely correlate with risk for fatal arrhythmia [28]. Indeed, many epidemiological studies suggest ambient $\mathrm{PM}_{2.5}$ exposure decreases HRV [1] and causes spontaneous arrhythmia and cardiac arrest [61]. Although sympathetic dominance likely drives $\mathrm{PM}_{2.5}$-induced cardiac arrhythmia and arrest, human studies have yet to confirm this link. In contrast, Hazari [62] demonstrated in hypertensive rats that diesel exhaust inhalation enhances sensitivity to drug-induced arrhythmia and cardiac arrest via a sympathetic pathway. Herein, we eschewed additional arrhythmogenic triggers, likely explaining the transience of our observations. Dose-dependent trends for Mobitz II AV block and HRV through the first exposure week culminated in significant changes on day 4, yet no similar cumulative effects appeared over the following two weeks, perhaps due to compensatory responses. The correlation of these arrhythmias with HRV, BRS, and ECG intervals further suggests their sympathetic etiology, but additional studies are needed to confirm this link. In contrast, the more benign Mobitz I AV block correlated with these parameters in the opposite direction, suggesting these arrhythmia types diverge in etiology and deserve careful distinction in subsequent studies.

It remains unclear whether pollutant exposures might precipitate sudden cardiac death by provoking tachy- or bradyarrythmias, but $\mathrm{PM}_{2.5}$ exposure appears to disproportionately associate with non-fatal tachyarrhythmias in humans. $\mathrm{PM}_{2.5}$ induces tachyarrhythmias almost exclusively in rodent models of surgically-induced myocardial infarction [63], whereas rodent models of hypertension or progressive cardiomyopathy repeatedly respond to $\mathrm{PM}_{2.5}$ with bradyarrhythmias resembling AV block Mobitz type II. These discrepancies may stem from inherent differences in cardiac phenotype between humans and rodents. Notably, in Mets rats PM-induced AV block Mobitz II events were inversely related to ventilatory pause and RMSSD, and their increase was entirely accounted for by AV block events uncoupled from acute respiratory disruptions that derive from vagal activation [24]. Ventilatory disturbances (spontaneous braking, tachypnea, or apnea) may initiate compensatory autonomic reflexes to resynchronize cardioventilatory rhythm [64], and abrupt increases in parasympathetic modulation can cause AV block Mobitz II events [65-67]. Mobitz II events inversely correlated with daily averages of RMSSD and PR interval (derived from 5-min intervals), suggesting a positive correlation in MetS rats between sympathetic dominance and these arrhythmias. Ostensibly, these Mobitz II events may have occurred via acute parasympathetic compensation to tonic elevations in sympathetic influence induced by PM. Although we did not test for acute shifts in autonomic balance, others have noted that concurrent increases in sympathetic and parasympathetic tone, or the transition from parasympathetic excitation to a sympathetic surge, may induce atrial and ventricular fibrillation [68].

AV block Mobitz II arrhythmias are considered arrhythmias with sufficient potential for full AV dissociation, complete heart block, and cardiac arrest such that they are a clinical indication for pacemaker implantation [69]. Repeat exposure to ten-fold higher $\mathrm{PM}_{2.5}$ levels has been shown to impair cardiac vagal neuron excitability [32], which in turn may shorten PR interval, impair AV conduction, and thus promote Mobitz II AV block arrhythmias. Finally, the $\mathrm{PM}_{2.5}$-induced QT shortening in MetS rats recapitulates findings in humans [70] and denotes an increased risk for arrhythmia and sudden cardiac death further corroborated by its correlations 
with arrhythmia. Ultimately, our observations indicate MetS increases susceptibility to $\mathrm{PM}_{2.5}$-induced autonomic imbalance with associated arrhythmia, but further studies are required to unveil the basis of this susceptibility.

\section{Strengths and limitations}

Photochemical reaction of the traffic aerosol with gaseous pollutants enhanced ecological validity by simulating ambient generation of SOA at a consistent rate, whereas denuders ensured gases were within environmental norms. Nevertheless, the different $\mathrm{PM}_{2.5}$ concentrations between $\mathrm{P}+$ SOA-exposed ND and MetS rats hinders statistical determination of whether a phenotype-aerosol interaction accounted for the effects in MetS-P + SOA rats. Moreover, the cause of differences in aerosol concentrations remains unclear, particularly as we do not have data characterizing vehicular traffic or PM composition. Although the reasons remain unclear, $\mathrm{P}+\mathrm{SOA}$ concentrations may have been lower for MetS rats due to diminished SOA production in the photoreaction chamber secondary to a higher primary PM concentration in the tunnel plenum, as primary particles act as sinks for radicals and thus prevent the formation of SOA. Concordant with this, the elemental carbon (EC) fraction was notably higher for the MetS aerosol exposure. Nevertheless, EC was low for environmental levels, indicating vehicular particles accounted for only a small portion of the $\mathrm{P}+\mathrm{SOA}$ mass for ND and MetS rats. Although MetS rats had greater physiologic responses at less than half the $\mathrm{PM}_{2.5}$ concentration of ND rats, it is also possible a higher dose might elicit blunted responses per our hypothesized doseresponse relationship. Consequently, inferences from this study should be tempered by the limited comparability between aerosol exposure concentrations for the MetS and ND rats. It should also be noted that roughly half of the $\mathrm{P}+$ SOA particles were in the ultrafine range $(<100 \mathrm{~nm})$. In urban airsheds of post-industrial nations, background ultrafine PM (UFP) concentrations have been recently observed at comparable or higher levels [57, 71, 72]. Nevertheless, comparisons of our findings to other studies primarily incorporating larger particles might be hindered by divergent kinetics due to a lower deposition fraction in the bronchioles and parenchyma and differential mucociliary clearance and inflammatory cell interactions. The enhanced deposition of UFP may also augment activation of irritant receptors and thus autonomic effects relative to AMP or larger particles. Contrary to this, interquartile increases in ambient AMP were followed by more overt impairments in RMSSD and ventricular repolarization in cardiac rehabilitation patients than interquartile increases in UFP [57].

MetS rats had higher HRV than ND rats prior to $\mathrm{PM}_{2.5}$ exposure. Although somewhat unconventional, these findings are consistent with daytime measures in high fructose-fed mice [34] and obese children [73], and may derive from unique dietary-induced features of the model such as baroreflexes involving parasympathetic compensation for fructose-induced hypertension. This seems particularly plausible given that baroreflex sensitivity was unaffected by fructose alone; however, we were unable to assess systolic pressure variability, which may have informed whether greater volatility in aortic pressure corresponded with increased parasympathetic modulation in MetS rats. We analyzed HRV using time domain, power domain, and non-linear parameters in 5min segments sampled continuously from waveforms while controlling for confounding arrhythmias and artifacts to provide an assessment generally more rigorous and comprehensive than conventional approaches (analysis for $30 \mathrm{~s}$ of every $5 \mathrm{~min} \mathrm{[6];} 4 \mathrm{~min}$ of every $10 \mathrm{~min}$ [46]; $60 \mathrm{~s}$ of every 5 min [45]).

It should be noted that the hypertension and hyperglycemia in these MetS rats recapitulates effects in the same strain, gender, and age fed the same formula for the same duration [6], which also induced insulin resistance (increased HOMA-IR) and hypertriglyceridemia. Concurrent with the hypertension and hyperglycemia that we observed, MetS rats also likely had similar insulin resistance and hypertriglyceridemia. Although we did not verify hypertriglyceridemia and insulin resistance in the present study, it is apparent that our model collectively satisfies the criteria for MetS.

Although we did not pharmacologically validate our assessment of spontaneous BRS slope here, the sequence method has been validated relative to conventional clinical assessments of BRS [23]. Furthermore, we recently observed decreases in both spontaneous and nitroprusside-derived BRS slope in a follow-up pilot with highway traffic tunnel PM-exposed rats (unpublished data). The discordance from our prior observations of enhanced BRS in PM-exposed tracheostomized dogs may derive from this prior exposure bypassing upper airway (e.g., nasal) irritant receptors, or it may derive from key differences between the rat model of MetS and otherwise normal canines. The lack of ECG in ND rats preclude any comparison of $\mathrm{PM}_{2.5}$-induced arrhythmia with MetS rats. Nevertheless, $\mathrm{PM}_{2.5}$-exposed MetS rats had disproportionate and concomitant depressions in HRV and BRS, which have been shown to more robustly predict cardiovascular mortality than non-sustained ventricular tachycardia [28]. Finally, our findings are relatively descriptive. While we believe that the confluence of physiologic effects of PM on Mets rats (RMSSD decline, BRS decline, PR shortening, QT shortening, and increased AV block Mobitz II arrhythmia) and their correlation with each other collectively suggest that MetS increases cardiovascular susceptibility to environmentally 
relevant levels of PM via decreases in parasympathetic modulation, confirmation of autonomic mediation requires more sophisticated studies involving molecular or neural interventions.

\section{Conclusions}

Traffic-derived $\mathrm{PM}_{2.5}$ exposure at ambient levels blunts parasympathetic influence over cardiovascular function, induces tachypnea, and alters cardiac repolarization while transiently increasing spontaneous arrhythmia in a rat model of MetS. Individuals with MetS may be more susceptible to the adverse cardiac effects of $\mathrm{PM}_{2.5}$ exposure, and exposure to traffic-derived $\mathrm{PM}_{2.5}$ at concentrations common in the U.S. may measurably harm cardiovascular health through dysfunction of the autonomic nervous system.

\section{Additional file}

Additional file 1: Supplemental Data, Tables S1-S6 and Figures S1-S3. (DOCX $94 \mathrm{~kb})$

\begin{abstract}
Abbreviations
ANS: autonomic nervous system; APB: atrial premature beat; AV: atrioventricular; BP: blood pressure; BPM: beats per minute; BRS: baroreflex sensitivity; CAPs: concentrated ambient particulates; CMD: count median diameter; CO: carbon monoxide; CPC: condensation particle counter; $\mathrm{CV}$ : coefficient of variation; $\mathrm{dP} / \mathrm{dt}_{\max }$ : maximum rate of increase in aortic pressure per beat; ECG: electrocardiogram; F: respiratory frequency; FA: filtered air; HF: high frequency power spectral HRV; HFrD: high fructose diet; HRV: heart rate variability; LF: low frequency power spectral HRV; MetS: metabolic syndrome; MMD: mass median diameter;

Ms.: milliseconds; $\mathrm{ND}$ : normal diet; $\mathrm{NO}$ : nitric oxide; $\mathrm{NO}_{x}$ : nitrogen oxides; $\mathrm{O}_{3}$ : ozone; $\mathrm{P}+\mathrm{SOA}$ : primary and secondary organic aerosols;

$\mathrm{PM}_{2.5}$ : particulate matter <2.5 um in diameter; PP: pulse pressure; RMSSD: root mean squared of successive differences; SD: Sprague Dawley; SDNN: standard deviation of normal interbeat intervals; SE: standard error; SMPS: scanning mobility particle sizer; TE: expiratory time; TI: inspiratory time; TT: total respiratory cycle time
\end{abstract}

\section{Acknowledgements}

The authors thank Dr. Denise Lamoureux (Harvard) for animal handling and data collection, and Mr. Daniel Riggs (University of Louisville) for statistical review. The authors also thank the U.S. Environmental Protection Agency and $\mathrm{NIH}$ National Heart, Lung, and Blood Institute for their generous support.

\section{Funding}

This publication was made possible by USEPA grants R83479701 and RD83479801. Its contents are solely the responsibility of the grantee and do not necessarily represent official views of the USEPA. USEPA does not endorse the purchase of any commercial products or services mentioned in the publication. APC was supported through NHLBI T-32 HL007118.

\section{Availability of data and materials}

Data supporting the findings are found within the manuscript and supplemental material. Raw data files will be provided by the corresponding author upon request.

\section{Authors' contributions}

APC designed, performed, and guided HRV, ECG, arrhythmia, and BRS analysis procedures, performed all statistical analyses, and wrote the manuscript. SMC, MSF, DHZ, TNGJ performed HRV, ECG, and arrhythmia analyses. BAC oversaw the statistical analysis design for time-series data. EAD oversaw acquisition of pulmonary and telemetry data. RDR and BSP conducted spontaneous BRS analyses. ALR and DMG performed supplemental non-linear HRV analyses. VP and JEL handled exposure engineering and aerosol characterization. JRH collaborated on study design. JJG performed study design and oversaw execution of the study. All authors read and approved of the final manuscript.

\section{Competing interests}

The authors declare that they have no competing interests.

\section{Consent for publication}

No human data were used for this study, and thus consent was not required.

\section{Ethics approval}

Harvard University's AAALAC International-accredited Institutional Animal Care and Use Committee approved all animal handling and experimental procedures.

\section{Publisher's Note}

Springer Nature remains neutral with regard to jurisdictional claims in published maps and institutional affiliations.

\section{Author details}

${ }^{1}$ Department of Environmental Health, Harvard T.H. Chan School of Public Health, Boston, MA, USA. ${ }^{2}$ Department of Physiology, Diabetes and Obesity Center, School of Medicine, University of Louisville, 580 South Preston Street, Delia Baxter Building, Room 404B, Louisville, KY 40202, USA. ${ }^{3}$ School of Medicine, University of São Paulo, São Paulo, Brazil. ${ }^{4}$ Faculty of Public Health, University of São Paulo, São Paulo, Brazil. ${ }^{5}$ Federal University of São Paulo, São Paulo, Brazil. ${ }^{6}$ Faculty of Health and Life Sciences, Oxford Brookes University, Oxford, UK. ${ }^{7}$ Department of Pathobiology, Michigan State University, East Lansing, MI, USA.

Received: 2 November 2016 Accepted: 15 May 2017

Published online: 25 May 2017

\section{References}

1. Brook RD, Rajagopalan S, Pope CA 3rd, Brook JR, Bhatnagar A, Diez-Roux AV, Holguin F, Hong Y, Luepker RV, Mittleman MA, et al. Particulate matter air pollution and cardiovascular disease: an update to the scientific statement from the American Heart Association. Circulation. 2010;121 (21):2331-78.

2. Aguilar M, Bhuket T, Torres S, Liu B, Wong RJ. Prevalence of the metabolic syndrome in the United States, 2003-2012. JAMA. 2015;313(19):1973-4.

3. Chen JC, Schwartz J. Metabolic syndrome and inflammatory responses to long-term particulate air pollutants. Environ Health Perspect. 2008; 116(5):612-7.

4. Park SK, Auchincloss AH, O'Neill MS, Prineas R, Correa JC, Keeler J, Barr RG, Kaufman JD, Diez Roux AV. Particulate air pollution, metabolic syndrome, and heart rate variability: the multi-ethnic study of atherosclerosis (MESA). Environ Health Perspect. 2010;118(10):1406-11.

5. Zhao X, Sun Z, Ruan Y, Yan J, Mukherjee B, Yang F, Duan F, Sun L, Liang R, Lian $\mathrm{H}$, et al. Personal black carbon exposure influences ambulatory blood pressure: air pollution and cardiometabolic disease (AIRCMD-China) study. Hypertension. 2014;63(4):871-7.

6. Wagner JG, Allen K, Yang HY, Nan B, Morishita M, Mukherjee B, Dvonch JT, Spino C, Fink GD, Rajagopalan S, et al. Cardiovascular depression in rats exposed to inhaled particulate matter and ozone: effects of diet-induced metabolic syndrome. Environ Health Perspect. 2014;122(1):27-33.

7. Sun L, Liu C, Xu X, Ying Z, Maiseyeu A, Wang A, Allen K, Lewandowski RP, Bramble LA, Morishita $M$, et al. Ambient fine particulate matter and ozone exposures induce inflammation in epicardial and perirenal adipose tissues in rats fed a high fructose diet. Part Fibre Toxicol. 2013;10:43.

8. Pope CA 3rd, Turner MC, Burnett RT, Jerrett M, Gapstur SM, Diver WR, Krewski D, Brook RD. Relationships between fine particulate air pollution, cardiometabolic disorders, and cardiovascular mortality. Circ Res. 2015; 116(1):108-15.

9. Tran LT, Yuen VG, McNeill JH. The fructose-fed rat: a review on the mechanisms of fructose-induced insulin resistance and hypertension. Mol Cell Biochem. 2009;332(1-2):145-59.

10. Patel J, Iyer A, Brown L. Evaluation of the chronic complications of diabetes in a high fructose diet in rats. Indian J Biochem Biophys. 2009;46(1):66-72.

11. Godleski JJ, Rohr AC, Kang CM, Diaz EA, Ruiz PA, Koutrakis P. Toxicological evaluation of realistic emission source aerosols (TERESA): introduction and overview. Inhal Toxicol. 2011;23(Suppl 2):1-10. 
12. Lamoureux DP, Diaz EA, Chung Y, Coull BA, Papapostolou V, Lawrence J, Sato R, Godleski JJ. Effects of fresh and aged vehicular particulate emissions on blood pressure in normal adult male rats. Air Qual Atmos Health. 2013; 6(2):407-18.

13. Diaz EA, Chung Y, Lamoureux DP, Papapostolou V, Lawrence J, Long MS, Mazzaro V, Buonfiglio H, Sato R, Koutrakis P, et al. Effects of fresh and aged traffic-related particles on breathing pattern, cellular responses, and oxidative stress. Air Qual Atmos Health. 2013;6(2):431-44.

14. Papapostolou V, Lawrence JE, Ferguson ST, Wolfson JM, Diaz EA, Godleski Jر, Koutrakis P. Development and characterization of an exposure generation system to investigate the health effects of particles from fresh and aged traffic emissions. Air Qual Atmos Health. 2013;6:419-29.

15. Papapostolou V, Lawrence JE, Ferguson ST, Wolfson JM, Koutrakis P. Development and evaluation of a countercurrent parallel-plate membrane diffusion denuder for the removal of gas-phase compounds from vehicular emissions. Inhal Toxicol. 2011;23(13):853-62.

16. Carll AP, Hazari MS, Perez CM, Krantz QT, King CJ, Haykal-Coates N, Cascio WE, Costa DL, Farraj AK. An autonomic link between inhaled diesel exhaust and impaired cardiac performance: insight from treadmill and dobutamine challenges in heart failure-prone rats. Toxicol Sci. 2013;135(2):425-36.

17. Wiklund U, Hornsten R, Karlsson M, Suhr OB, Jensen SM. Abnormal heart rate variability and subtle atrial arrhythmia in patients with familial amyloidotic polyneuropathy. Ann Noninvasive Electrocardiol. 2008;13(3):249-56.

18. Kleiger RE, Miller JP, Bigger JT Jr, Moss AJ. Decreased heart rate variability and its association with increased mortality after acute myocardial infarction. Am J Cardiol. 1987:59(4):256-62.

19. Carll AP, Hazari MS, Perez CM, Krantz QT, King CJ, Winsett DW, Costa DL, Farraj AK. Whole and particle-free diesel exhausts differentially affect cardiac electrophysiology, blood pressure, and autonomic balance in heart failureprone rats. Toxicol Sci. 2012;128(2):490-9.

20. Carll AP, Haykal-Coates N, Winsett DW, Rowan WH 3rd, Hazari MS, Ledbetter AD, Nyska A, Cascio WE, Watkinson WP, Costa DL, et al. Particulate matter inhalation exacerbates cardiopulmonary injury in a rat model of isoproterenol-induced cardiomyopathy. Inhal Toxicol. 2010;22(5):355-68.

21. Tartiere JM, Tabet JY, Logeart D, Tartiere-Kesri L, Beauvais F, Chavelas C, Cohen Solal A. Noninvasively determined radial $\mathrm{dP} / \mathrm{dt}$ is a predictor of mortality in patients with heart failure. Am Heart J. 2008;155(4):758-63.

22. Germano G, Angotti S, Muscolo M, D'Auria F, Giordano M. The (dP/dt)max derived from arterial pulse waveforms during $24 \mathrm{~h}$ blood pressure oscillometric recording. Blood Press Monit. 1998:3(3):213-6.

23. Pinna GD, Maestri R, La Rovere MT. Assessment of baroreflex sensitivity from spontaneous oscillations of blood pressure and heart rate: proven clinical value? Physiol Meas. 2015;36(4):741-53.

24. Hatridge J, Haji A, Perez-Padilla JR, Remmers JE. Rapid shallow breathing caused by pulmonary vascular congestion in cats. J Appl Physiol (1985). 1989;67(6):2257-64.

25. Murakawa Y, Inoue H, Nozaki A, Sugimoto T. Role of sympathovagal interaction in diurnal variation of QT interval. Am J Cardiol. 1992;69(4):339-43.

26. Pirola FT, Potter EK. Vagal action on atrioventricular conduction and its inhibition by sympathetic stimulation and neuropeptide $Y$ in anaesthetised dogs. J Auton Nerv Syst. 1990;31(1):1-12.

27. Uchida Y. Tachypnea after stimulation of afferent cardiac sympathetic nerve fibers. Am J Phys. 1976;230(4):1003-7.

28. La Rovere MT, Pinna GD, Hohnloser SH, Marcus FI, Mortara A, Nohara R, Bigger JT Jr, Camm AJ, Schwartz PJ, Tone AIA, et al. Baroreflex sensitivity and heart rate variability in the identification of patients at risk for lifethreatening arrhythmias: implications for clinical trials. Circulation. 2001; 103(16):2072-7.

29. Carnevali L, Sgoifo A. Vagal modulation of resting heart rate in rats: the role of stress, psychosocial factors, and physical exercise. Front Physiol. 2014;5:118.

30. Cohen MA, Taylor JA. Short-term cardiovascular oscillations in man: measuring and modelling the physiologies. J Physiol. 2002;542(Pt 3):669-83.

31. Taylor JA, Myers CW, Halliwill JR, Seidel H, Eckberg DL. Sympathetic restraint of respiratory sinus arrhythmia: implications for vagal-cardiac tone assessment in humans. Am J Physiol Heart Circ Physiol. 2001;280(6):H2804-14.

32. Pham H, Bonham AC, Pinkerton KE, Chen CY. Central neuroplasticity and decreased heart rate variability after particulate matter exposure in mice. Environ Health Perspect. 2009;117(9):1448-53.

33. Wilker E, Mittleman MA, Litonjua AA, Poon A, Baccarelli A, Suh H, Wright RO, Sparrow D, Vokonas P, Schwartz J. Postural changes in blood pressure associated with interactions between candidate genes for chronic respiratory diseases and exposure to particulate matter. Environ Health Perspect. 2009;117(6):935-40

34. Farah V, Elased KM, Morris M. Genetic and dietary interactions: role of angiotensin AT1a receptors in response to a high-fructose diet. Am J Physiol Heart Circ Physiol. 2007;293(2):H1083-9.

35. Bartoli CR, Wellenius GA, Diaz EA, Lawrence J, Coull BA, Akiyama I, Lee LM, Okabe K, Verrier RL, Godleski JJ. Mechanisms of inhaled fine particulate air pollution-induced arterial blood pressure changes. Environ Health Perspect. 2009:117(3):361-6.

36. Dresing TJ, Wilkoff BL. Bradyarrhythmias. Curr Treat Options Cardiovasc Med. 2001;3(4):291-8.

37. Bayes de Luna A, Coumel P, Leclercq JF. Ambulatory sudden cardiac death: mechanisms of production of fatal arrhythmia on the basis of data from 157 cases. Am Heart J. 1989;117(1):151-9.

38. Soliman EZ, Cammarata M, Li Y. Explaining the inconsistent associations of PR interval with mortality: the role of P-duration contribution to the length of PR interval. Heart Rhythm. 2014;11(1):93-8.

39. Zhang Y, Post WS, Dalal D, Blasco-Colmenares E, Tomaselli GF, Guallar E. QTinterval duration and mortality rate: results from the third National Health and nutrition examination survey. Arch Intern Med. 2011;171(19):1727-33.

40. Hazari MS, Griggs J, Winsett DW, Haykal-Coates N, Ledbetter A, Costa DL, Farraj AK. A single exposure to acrolein desensitizes baroreflex responsiveness and increases cardiac arrhythmias in normotensive and hypertensive rats. Cardiovasc Toxicol. 2014;14(1):52-63.

41. Conklin DJ, Haberzettl P, Lee J, Srivastava S. Environmental Aldehydes and cardiovascular disease. In: Bhatnagar A, editor. Environmental cardiology: pollution and heart disease. Cambridge: Royal Society of Chemistry; 2011. p. 301-70.

42. Peters A, Hampel R, Cyrys J, Breitner S, Geruschkat U, Kraus U, Zareba W, Schneider A. Elevated particle number concentrations induce immediate changes in heart rate variability: a panel study in individuals with impaired glucose metabolism or diabetes. Part Fibre Toxicol. 2015;12:7.

43. Cosselman KE, Krishnan RM, Oron AP, Jansen K, Peretz A, Sullivan JH, Larson TV, Kaufman JD. Blood pressure response to controlled diesel exhaust exposure in human subjects. Hypertension. 2012;59(5):943-8.

44. Devlin RB, Smith CB, Schmitt MT, Rappold AG, Hinderliter A, Graff D, Carraway MS. Controlled exposure of humans with metabolic syndrome to concentrated ultrafine ambient particulate matter causes cardiovascular effects. Toxicol Sci. 2014;140(1):61-72

45. Farraj AK, Haykal-Coates N, Winsett DW, Gilmour MI, King C, Krantz QT, Richards J, Hazari MS. Comparative electrocardiographic, autonomic and systemic inflammatory responses to soy biodiesel and petroleum diesel emissions in rats. Inhal Toxicol. 2015;27(11):564-75.

46. Carll AP, Haykal-Coates N, Winsett DW, Hazari MS, Ledbetter AD, Richards JH, Cascio WE, Costa DL, Farraj AK Cardiomyopathy confers susceptibility to particulate matterinduced oxidative stress, vagal dominance, arrhythmia and pulmonary inflammation in heart failure-prone rats. Inhal Toxicol. 2015;27(2):100-12.

47. Farraj AK, Hazari MS, Haykal-Coates N, Lamb C, Winsett DW, Ge Y, Ledbetter AD, Carll AP, Bruno M, Ghio A, et al. ST depression, arrhythmia, vagal dominance, and reduced cardiac micro-RNA in particulate-exposed rats. Am J Respir Cell Mol Biol. 2011;44(2):185-96.

48. Davoodi G, Sharif AY, Kazemisaeid A, Sadeghian S, Farahani AV, Sheikhvatan M, Pashang M. Comparison of heart rate variability and cardiac arrhythmias in polluted and clean air episodes in healthy individuals. Environ Health Prev Med. 2010;15(4):217-21.

49. Pope CA 3rd, Verrier RL, Lovett EG, Larson AC, Raizenne ME, Kanner RE, Schwartz J, Villegas GM, Gold DR, Dockery DW. Heart rate variability associated with particulate air pollution. Am Heart J. 1999;138(5 Pt 1):890.

50. Routledge HC, Manney S, Harrison RM, Ayres JG, Townend JN. Effect of inhaled sulphur dioxide and carbon particles on heart rate variability and markers of inflammation and coagulation in human subjects. Heart. 2006;92(2):220.

51. Han Y, Fan ZD, Yuan N, Xie GQ, Gao J, De W, Gao XY, Zhu GQ. Superoxide anions in the paraventricular nucleus mediate the enhanced cardiac sympathetic afferent reflex and sympathetic activity in renovascular hypertensive rats. J Appl Physiol (1985). 2011;110(3):646-52.

52. Chuang HC, Hsueh TW, Chang CC, Hwang JS, Chuang KJ, Yan YH, Cheng TJ. Nickel-regulated heart rate variability: the roles of oxidative stress and inflammation. Toxicol Appl Pharmacol. 2013;266(2):298-306.

53. Hemmingsen JG, Rissler J, Lykkesfeldt J, Sallsten G, Kristiansen J, Moller PP, Loft S. Controlled exposure to particulate matter from urban street air is associated with decreased vasodilation and heart rate variability in overweight and older adults. Part Fibre Toxicol. 2015;12:6. 
54. Vora R, Zareba W, Utell MJ, Pietropaoli AP, Chalupa D, Little EL, Oakes D, Bausch J, Wiltshire J, Frampton MW. Inhalation of ultrafine carbon particles alters heart rate and heart rate variability in people with type 2 diabetes. Part Fibre Toxicol. 2014;11:31.

55. Devlin RB, Ghio AJ, Kehrl H, Sanders G, Cascio W. Elderly humans exposed to concentrated air pollution particles have decreased heart rate variability. Eur Respir J Suppl. 2003;40:76s-80s.

56. de Hartog JJ, Lanki T, Timonen KL, Hoek G, Janssen NA, Ibald-Mulli A, Peters A, Heinrich J, Tarkiainen TH, van Grieken R, et al. Associations between PM2.5 and heart rate variability are modified by particle composition and beta-blocker use in patients with coronary heart disease. Environ Health Perspect. 2009;117(1):105.

57. Rich DQ, Zareba W, Beckett W, Hopke PK, Oakes D, Frampton MW, Bisognano J, Chalupa D, Bausch J, O'Shea K, et al. Are ambient ultrafine, accumulation mode, and fine particles associated with adverse cardiac responses in patients undergoing cardiac rehabilitation? Environ Health Perspect. 2012;120(8):1162-9.

58. Rose BA, Force T, Wang Y. Mitogen-activated protein kinase signaling in the heart: angels versus demons in a heart-breaking tale. Physiol Rev. 2010;90(4): 1507-46.

59. Tilley DG. G protein-dependent and G protein-independent signaling pathways and their impact on cardiac function. Circ Res. 2011;109(2):217-30.

60. Lewin G, Matus M, Basu A, Frebel K, Rohsbach SP, Safronenko A, Seidl MD, Stumpel F, Buchwalow I, Konig S, et al. Critical role of transcription factor cyclic AMP response element modulator in beta1-adrenoceptor-mediated cardiac dysfunction. Circulation. 2009;119(1):79-88.

61. Teng TH, Williams TA, Bremner A, Tohira H, Franklin P, Tonkin A, Jacobs I, Finn J. A systematic review of air pollution and incidence of out-of-hospital cardiac arrest. J Epidemiol Community Health. 2014;68(1):37-43.

62. Hazari MS, Haykal-Coates N, Winsett DW, Krantz QT, King C, Costa DL, Farraj AK. TRPA1 and sympathetic activation contribute to increased risk of triggered cardiac arrhythmias in hypertensive rats exposed to diesel exhaust. Environ Health Perspect. 2011;119(7):951-7.

63. Wellenius GA, Batalha JRF, Diaz EA, Lawrence J, Coull B, Katz T, Verrier RL, Godleski JJ. Cardiac effects of carbon monoxide and ambient particles in a rat model of myocardial infarction. Toxicol Sci. 2004:367-76.

64. Dick TE, Hsieh YH, Dhingra RR, Baekey DM, Galan RF, Wehrwein E, Morris KF. Cardiorespiratory coupling: common rhythms in cardiac, sympathetic, and respiratory activities. Prog Brain Res. 2014;209:191-205.

65. Castellanos A, Sung RJ, Cunha D, Myerburg RJ. His bundle recordings in paroxysmal atrioventricular block produced by carotid sinus massage. Br Heart J. 1974;36(5):487-91.

66. Hotta H, Lazar J, Orman R, Koizumi K, Shiba K, Kamran H, Stewart M. Vagus nerve stimulation-induced bradyarrhythmias in rats. Auton Neurosci. 2009; 151(2):98-105

67. Massie B, Scheinman MM, Peters R, Desai J, Hirschfeld D, O'Young J. Clinical and electrophysiologic findings in patients with paroxysmal slowing of the sinus rate and apparent Mobitz type II atrioventricular block. Circulation. 1978;58(2):305-14.

68. Tan AY, Verrier RL. The role of the autonomic nervous system in cardiac arrhythmias. Handb Clin Neurol. 2013;117:135-45.

69. Epstein AE, JP DM, Ellenbogen KA, Estes NA 3rd, Freedman RA, Gettes LS, Gillinov AM, Gregoratos G, Hammill SC, Hayes DL, et al. ACC/AHA/HRS 2008 guidelines for device-based therapy of cardiac rhythm abnormalities: a report of the American College of Cardiology/American Heart Association task force on practice guidelines (writing Committee to revise the ACC/ AHA/NASPE 2002 guideline update for implantation of cardiac pacemakers and Antiarrhythmia devices) developed in collaboration with the American Association for Thoracic Surgery and Society of Thoracic Surgeons. J Am Coll Cardiol. 2008;51(21):e1-62.

70. Schneider A, Neas LM, Graff DW, Herbst MC, Cascio WE, Schmitt MT, Buse JB, Peters A, Devlin RB. Association of cardiac and vascular changes with ambient PM2.5 in diabetic individuals. Part Fibre Toxicol. 2010;7:14.

71. Wang F, Ketzel M, Ellermann T, Wahlin P, Jensen SS, Fang D, Massling A. Particle number, particle mass and NOx emission factors at a highway and an urban street in Copenhagen. Atmos Chem Phys. 2010;10(6):2745-64.

72. Keuken MP, Moerman M, Voogt M, Zandveld P, Verhagen H, Stelwagen U, de Jonge D. Particle number concentration near road traffic in Amsterdam (the Netherlands): comparison of standard and real-world emission factors. Atmos Environ. 2016;132:345-55.

73. Vanderlei FM, Vanderlei LCM. Carlos de Abreu L, Garner DM: entropic analysis of HRV in obese children. Int Arch Med. 2015;8(200):1-9.

\section{Submit your next manuscript to BioMed Central and we will help you at every step:}

- We accept pre-submission inquiries

- Our selector tool helps you to find the most relevant journal

- We provide round the clock customer support

- Convenient online submission

- Thorough peer review

- Inclusion in PubMed and all major indexing services

- Maximum visibility for your research

Submit your manuscript at www.biomedcentral.com/submit 